15. Short, E. M., Conn, H. O., Snodgrass, P. J., Campbell, A. G.. and Rosenberg, L. E.: Evidence for $\mathrm{X}$-linked dominant inheritance of ornithine transcarbamylase deficiency. New Engl. J. Med., 288: 7 (1973).

16. Snodgrass, P. J., and Parry, D. J.: The kinetics of serum ornithine carbamyltransferase. J. Lab. Clin. Med., 73: 940 (1969).

17. Suzuki, Y., Berman, P. H., and Suzuki, K.: Detection of Tay-Sach's disease heterozygotes by assay of hexosaminidase $\mathrm{A}$ in serum and leukocytes. J. Pediat., 78: 643 (1971).

18. Tedesco, T. A., and Mellman, W. J.: Argininosuccinate synthetase activity and

Copyright (c) 1975 International Pediatric Research Foundation, Inc. citrultine metabolism in cells cultured from a citrullinemic subject. Proc. Nat. Acad. Sci. U. S. A., 57: 829 (1967).

19. Wolfe, D. M., and Gatfield, P. D.: Unpublished data.

20. This research was supported by Grant 413 from The Ontario Mental Health Foundation, Toronto, Ontario, Canada.

21. Requests for reprints should be addressed to: D. M. Wolfe, M.D., Children's Psychiatric Research Institute, P. O. Box 2460, London, Ontario, Canada. 22. Accepted for publication March 4, 1975.

Pediat. Res. 9: 535-541 (1975)

Brittle diabetes mellitus hyperglycemia catecholamines hypoglycemia glucose Somogyi syndrome

\title{
Interaction of Endogenous Growth Hormone, Cortisol, and Catecholamines with Blood Glucose in Children with Brittle Diabetes Mellitus
}

\author{
ERIKA BRUCK ${ }^{(61)}$ AND MARGARET H. MacGILLIVRAY \\ Department of Pediatrics, School of Medicine, State University of New York at Buffalo and Children's Hospital of \\ Buffalo, Buffalo, New York, USA
}

\section{Extract}

Hormonal balance was studied in eight insulin-treated diabetic children who had excessive glycosuria. Glucose, growth hormone, and cortisol in plasma were determined every $0.5 \mathrm{hr}$ for $48 \mathrm{hr}$. Total catecholamines and glucose were measured and tests for ketones done in 2-hourly collections of urine.

Intermittent hypoglycemia as low as $20 \mathrm{mg} / 100 \mathrm{ml}$ and swings of the blood sugar curve by $200-300 \mathrm{mg} / 100 \mathrm{ml}$ within $2-4 \mathrm{hr}$ were documented in most patients.

Peaks of growth hormone concentration in plasma $(8-78 \mathrm{ng} / \mathrm{ml})$ followed almost every sharp fall in blood glucose; these peaks were usually followed by abrupt rises of glucose and prolonged hyperglycemia.

Cortisol concentration was usually within the high normal range; there was no consistent relationship to the concentration of glucose.

Urinary excretion of catecholamines in most patients was between 1 and $6 \mu \mathrm{g} / \mathrm{hr}$; three patients excreted up to $8-23 \mu \mathrm{g} / \mathrm{hr}$ during short periods and up to $190 \mu \mathrm{g}$ in $24 \mathrm{hr}$. The causes for the high excretion of catecholamines are unknown and may not have included hypoglycemia.

\section{Speculation}

Excessive production of growth hormone and possibly other hormonal antagonists of insulin may be provoked by hypoglycemia and other physiologic stresses in diabetic children. The resulting hyperglycemia may prompt the administration of increasing doses of insulin which, in turn, contribute to a vicious cycle of hypoglycemia alternating with hyperglycemia.

Hyperglycemia, excessive glycosuria, and ketonuria, alternating with occasional aglycosuria, may occur in diabetic patients who are treated with large amounts of insulin. Somogyi $(50,52)$ believed that excessive amounts of insulin resulting in hypoglycemia, often latent, were the cause of the hyperglycemia; he demonstrated that severely incapacitated patients suffering from unstable diabetes could be rehabilitated and their glycosuria could be reduced, apparently paradoxically, by gradual reduction of their insulin dose to a fraction of the former one. Similar clinical observations were made by others $(5,44)$, who confirmed the benefits of reduction of the insulin dosage.

The pathogenesis of the "Somogyi syndrome" was a matter of speculation before the development of laboratory methods which permitted investigation of hormonal balance. Somogyi $(50,51)$ suspected "hormones of the pituitary-adrenal system" to play a role, particularly epinephrine. A satisfactory hypothesis would have to explain both the rapid rise of blood glucose and the prolonged state of insulin resistance which have been demonstrated after hypoglycemia.

The purposes of our studies were $(I)$ documentation of the existence of sequences of hypoglycemia causing hyperglycemia in diabetic children who have excessive glycosuria (such sequences have been reported by us (8)) and (2) elucidation of the nature of hormonal responses to hypoglycemia. At least four hormones are now known to cause elevation of blood glucose: growth hormone, cortisol, epinephrine, and glucagon; some or all of these may be produced in response to hypoglycemia.

\section{MATERIALS AND METHODS}

Eight children were studied. The clinical features of the course of the five boys and three girls and the details of the clinical study performed in the Clinical Research Center have been reported in an earlier communication (8). Seven of these children had exhibited excessive glycosuria and occasional ketonuria which 
could not be controlled and even seemed to increase when insulin doses were raised. Patient $J B$, case 6 , was admitted tio the study as a well regulated "control" to the patients with suspected Somogyi syndrome. He was considered to be onie of the best regulated and most cooperative and disciplined patients in the diabetic clinic of the Children's Hospital. Qualitative tests for sugar (Clinitest tablets) and acetone performed twice daily at home and quantitative measurements performed four to five times a year in the clinic always showed a slight glycosuria and had never shown acetone in his urine.

With the exception of case 1 , the patients were ambulatory and in their usual state of health. Highly trained nurses obtained all the blood and urine specimens and kept the children in good spirits. The children did not awake when blood specimens were obtained at night but were awakened every $2 \mathrm{hr}$ to urinate.

The secretion of growth hormone and cortisol was evaluated by measuring their concentrations in plasma at 0.5 -hourly intervals, that of epinephrine by measuring the excretion of total catecholamines in 2-hourly porticiss of urine. Adequate methodology for the evaluation of glucagon activity was not available in the laboratory when these studits began. Observations in the early phases of the study indicated that a $24-\mathrm{hr}$ period was insufficient for elucidation of the course of glucose and hormonal patterns; $48 \mathrm{hr}$ was accepted as the mirimal time required and yet the maximal time that could be impused on the children. Hemoglobin and hematocrit were determined before and after the studies; in no case was a significant fall in hemoglobin observed.

\section{CHEMICAL METHODS}

Blood glucose was determined by the Somogyi-Nelson method (42), using $0.1 \mathrm{ml}$ whole blood. The remainder of the blood was immediately centrifuged and the plasma frozen for later analysis. Human growth hormone was measured by the double antibody radioimmunoassay technique $(18,47)$. Corticosteroids in plasma were measured in the laboratory of Dr. W. R. Slaunwhite by the method of Murphy (41). Total catecholamines in urine were measured by the method of Jacobs et al. (25) at Bio-Science Laboratories (59).

\section{RESULTS}

\section{GLUCOSE LEVELS}

As described in an earlier report (8), hypoglycemic episodes, lasting between 1 and $22 \mathrm{hr}$, occurred at varying and unpredictable times in seven of the eight patients studied, including the boy who was admitted as a control subject. Figures 1-5 illustrate some of these episodes which were often terminated by abrupt rises of blood sugar. Fluctuations of blood sugar values exceeded 200-300 $\mathrm{mg} / 100 \mathrm{ml}$ in either direction within $2-4 \mathrm{hr}$ on many occasions.

\section{GROWTH HORMONE}

Peaks of growth hormone concentration followed almost every sharp fall of blood glucose. In 17 studies performed in 7 patients, (observations on $J D$ are not included in this analysis) there were 57 falls in glucose by more than $100 \mathrm{mg} / 100 \mathrm{ml}$ in $2 \mathrm{hr}$. Table 1 indicates that 43 of these falls $(75 \%)$ were accompanied or followed by a rise of growth hormone concentration above $8 \mathrm{ng} / \mathrm{ml}$ within 1 hr. There were 19 episodes of hypoglycemia (glucose $<60 \mathrm{mg} / 100$ $\mathrm{ml}$ ); on 16 occasions, including all 12 when the glucose level was below $50 \mathrm{mg} / 100 \mathrm{ml}$, there was a peak of growth hormone concentration. Some of the peak levels of growth hormone were above 40 and up to $78 \mathrm{ng} / \mathrm{ml}$ (Figs. 1,6).

"Sleep peaks" of growth hormone were not suppressed by hyperglycemia (see Fig. 3, second night). $K L$ and $J D$ (Fig. 6) had many high spikes of growth hormone concentration, night and day, independently of blood sugar levels, other than the ones which may have been responses to sharp falls of blood sugar; in $J D$, the concentration was $40-71 \mathrm{ng} / \mathrm{ml}$ on 16 occasions in $48 \mathrm{hr}$. Most, although not all, of the peaks of growth hormone concentration were followed by a sharp rise of blood glucose which often remained elevated for several hours, sometimes days (Figs. 1-4).

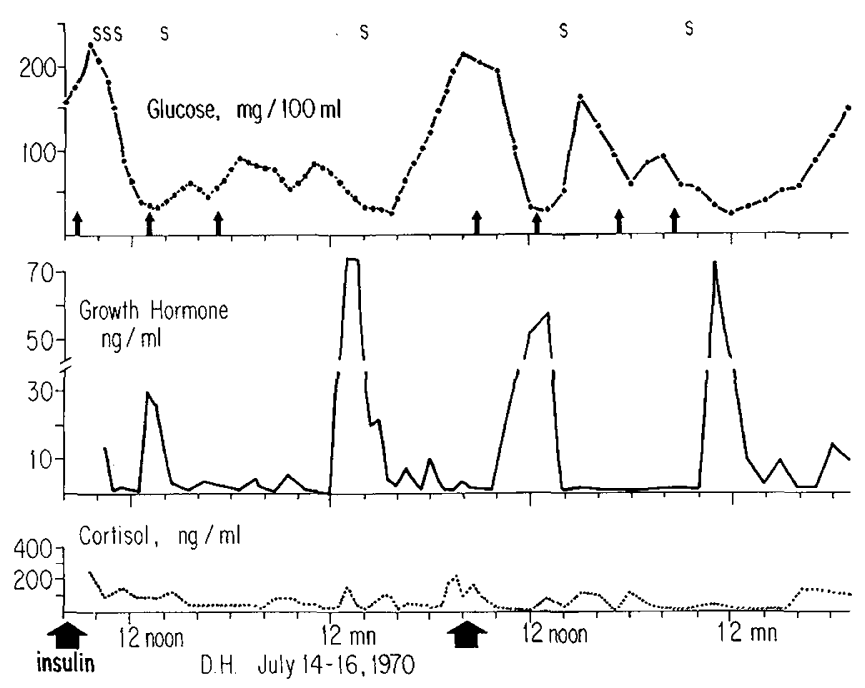

Fig. 1. Levels of glucose in blood and growth hormone and cortisol in plasma for DH, July 14-16, 1970. Insulin dose was 38 units NPH. Urine was collected for four periods of $12 \mathrm{hr}$ each and was free of sugar and acetone throughout the $48 \mathrm{hr}$. The arrows at the bottom of the glucose curve indicate the times of meals. $S$ above the curve indicates times of seizures. The broad arrows in the time scale indicate times of insulin injections.

Table 1. Relation between rapid fall or low level of glucose concentration in blood with elevation of growth hormone ${ }^{1}$

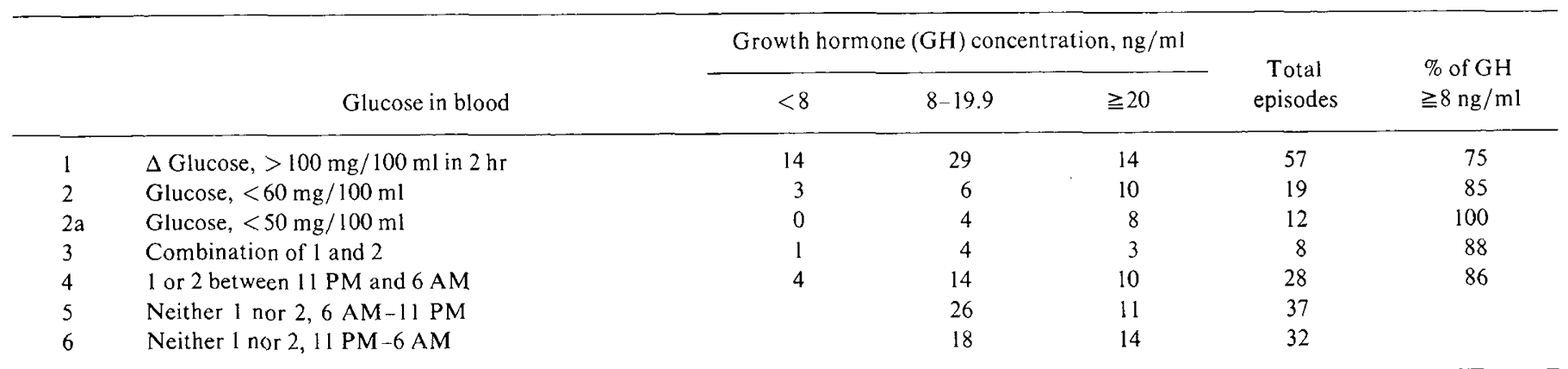

${ }^{1}$ The cases of row 3 are included in the figures of rows $I$ and 2. When they are subtracted from rows $I$ and 2 , the percentage of episodes followed by elevation of GH does not change in either group. Rows 4 and 6 are listed because growth hormone spikes at these times might be attributed to deep sleep, aithough sleep was not monitored in all cases and on some occasions it is known that the children were not asleep at the times of the growth hormone spikes. 


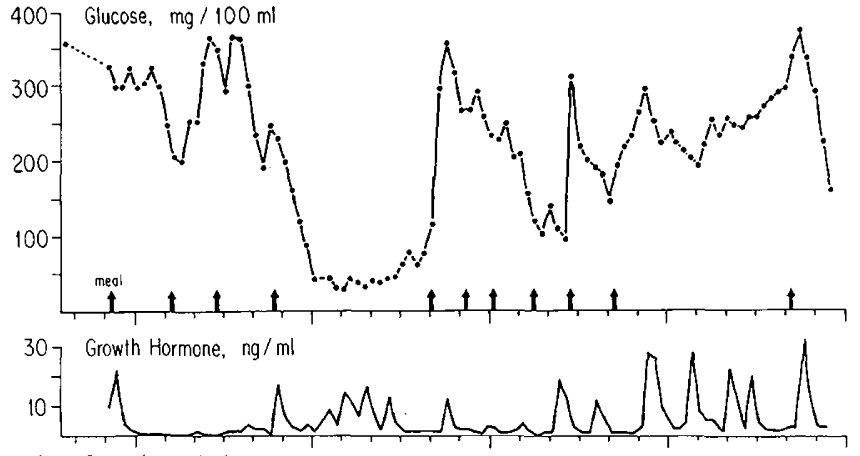

600 _ Cortisol, $\mathrm{ng} / \mathrm{ml}$

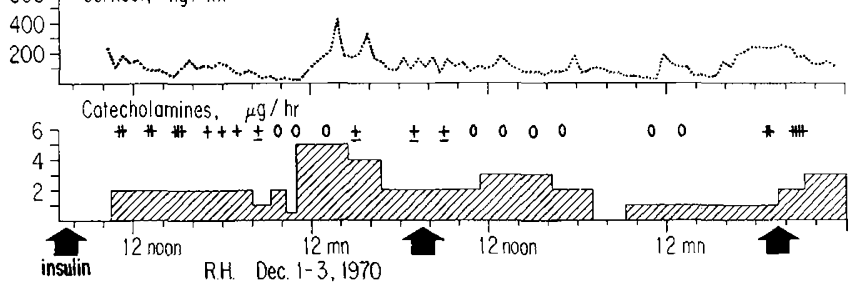

Fig. 2. Glucose in blood, growth hormone and cortisol in plasma, and total catecholamines in urine of $\mathrm{RH}$, December 1-3, 1970. Acetone reaction, in terms of $0-4+$ for each 2 -hr urine collection, is indicated by the symbols above the catecholamine diagram. Insulin dose: Ultralente 12 units, regular 5 units.

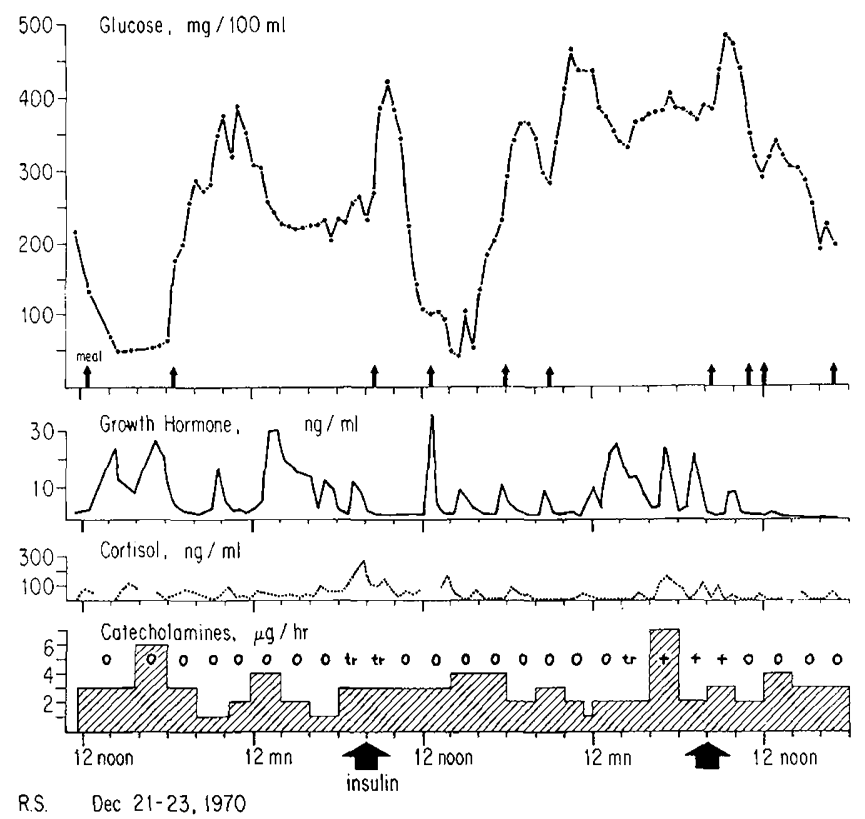

Fig. 3. Glucose in blood, growth hormone and cortisol in plasma, and total catecholamines in urine of $R S$, December 21-23, 1970. The urine contained small amounts of acetone between $2 \mathrm{AM}$ and $10 \mathrm{AM}$ on December 23, as indicated. Insulin dose: Ultralente 13 units, regular 8 units.

\section{CORTISOL}

In general, the corticosteroid levels fluctuated in the normal range $(27,31)$. Although some peaks of corticosteroid secretion were seen coincident with nadirs or rapid falls in glucose, these could not be distinguished in height or in number from frequent peaks without relationship to the fluctuations in glucose concentration. However, the two youngest patients had multiple peaks during the day and also at midnight (see fig. 2) which equaled the height of those at 8:00 AM; the levels for $J C$ were relatively high throughout the study. The 4:00 PM peak on July 15, 1971 for $J B$ equaled his relatively high 7:00 AM peak of $300 \mathrm{ng} / \mathrm{ml}$ (see Fig. 5).

The corticosteroid data for 14 of the studies were subjected to
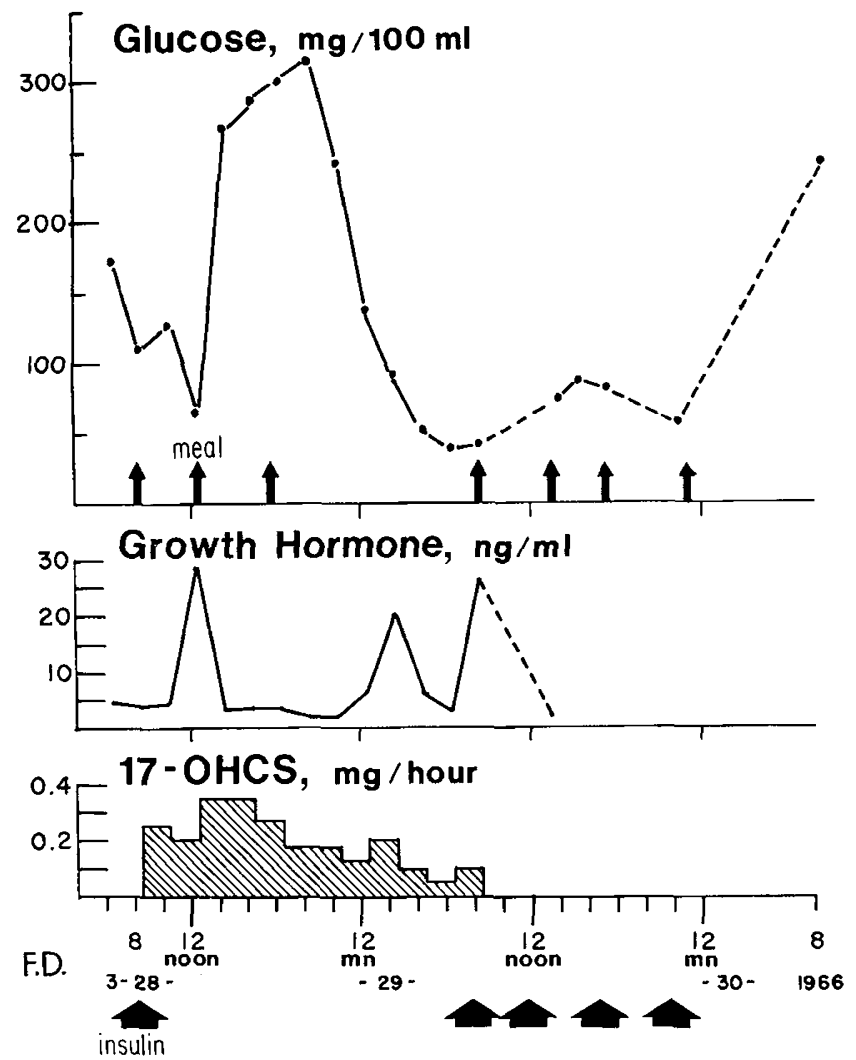

Fig. 4. Glucose in blood, growth hormone in plasma, and 17-hydroxycorticoids in urine of $F D$, March 28-30, 1966. Insulin dose on March 28: 65 units of protamine zinc insulin and 10 units of regular. On March 29, 16 units of regular insulin each were given before breakfast, lunch, and supper and 6 units at $10 \mathrm{PM}$, before the bedtime snack. There were no symptoms of hypoglycemia in the morning of March 29 when blood glucose concentration was $37 \mathrm{mg} / 100 \mathrm{ml}$. Note that the time scale is condensed compared with those of the other illustrations. (This patient was studied before the present protocol was adopted.) 17-OHCS: 17-OH-corticoids.

statistical evaluation and compared with those observed in normal children in the same age group by the same method (27). There is a suggestion that the peak time of the circadian rhythm is more variable $(2: 50 \mathrm{AM}-11: 32 \mathrm{AM})$ and that both the mean plasma level and the mean total output are higher and more variable in the diabetic children than in the normal children. However, there was no difference in the total time the adrenal gland was secreting cortisol (27). The highest figures for mean total output were obtained for $J C$ (three studies), $R H$ (two studies), and $J B$.

An extreme elevation of corticosteroids in plasma was seen only on one occasion, in $D H$ : four peaks of $1,150-2,150 \mathrm{ng} / \mathrm{ml}$ between midnight and 6:00 AM on July 10,1970 (not illustrated). At this time, which followed $22 \mathrm{hr}$ of hypoglycemia between July 7 and July 8, 1970 (8), the patient had severe epilepsy and almost continuous petit mal, but no major seizures were observed at the time of these plasma corticosteroid peaks. On other days with similar convulsive activity, plasma corticosteroid levels were not high (see Fig. 1). A moderately high plasma level of corticosteroids, $430 \mathrm{ng} / \mathrm{ml}$, occurred in $R H$ at 2:00 AM on December 2, 1970 (Fig. 2); this coincided in time with a nadir of blood glucose (33 $\mathrm{mg} / 100 \mathrm{ml}$ ) but also with a painful effort to reinsert the indwelling needle in his veins in the middle of the night.

\section{CATECHOLAMINE EXCRETION}

Total urinary catecholamine excretion was initially in the "normal" range (56) in $D H$ who had had prolonged and repeated hypoglycemia for years; later on, values of $5-8 \mu \mathrm{g} / \mathrm{hr}$ were occassionally observed for him, not necessarily in response to low 

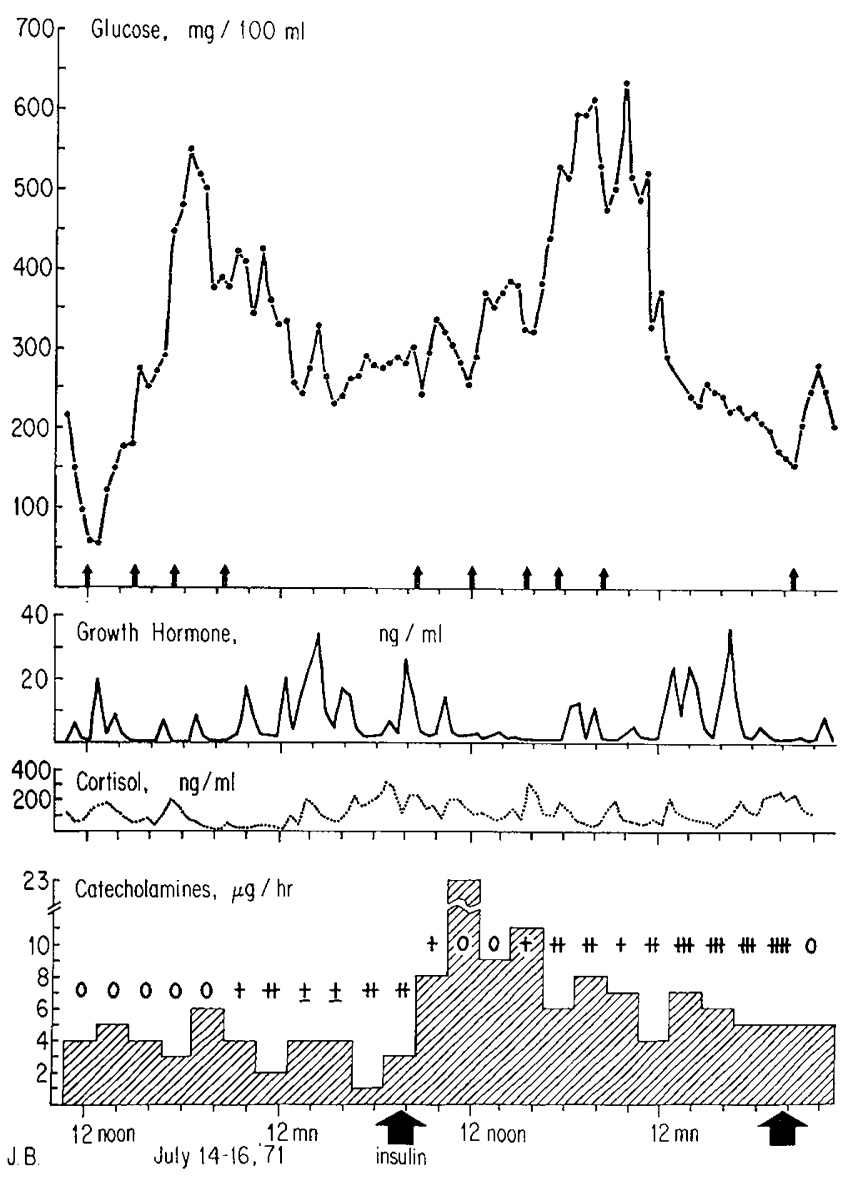

Fig. 5. Glucose in blood, growth hormone and cortisol in plasma, and total catecholamines in urine of $J B$, July 14-16, 1971. Symbols for acetone as in Figure 2. Insulin dose: protamine zinc insulin 34 units, regular 8 units. At 12:15 PM on July 16, the patient appeared pale, perspiring, hungry; blood sugar was not measured at that time.

blood glucose. $J C$, aged 5 years, excreted such large amounts of catecholamines when first studied in February 1971, that pheochromocytoma was suspected, particularly since she also had intermittent hypertension. The large catecholamine excretion was not immediately preceded by hypoglycemia, although the patient had had documented blood sugar levels as low as $48 \mathrm{mg} / 100 \mathrm{ml}$ within a few months before and after the observation.

$J B$ (Fig. 5), whose urine at home had contained only $2.2 \mathrm{~g}$ glucose in $24 \mathrm{hr} 2$ weeks before the study, excreted $193 \mathrm{~g}$ glucose $(0.2-19.8 \mathrm{~g} / \mathrm{hr})$ and a total of $198 \mu \mathrm{g}$ catecholamines in the second $24 \mathrm{hr}$ of the study. His blood pressure remained normal.

A third patient, $J D$, excreted over $100 \mu \mathrm{g}$ catecholamines in 24 hr with a maximum of $8 \mu \mathrm{g} / \mathrm{hr}$; this was the same patient who had extremely high peaks of growth hormone concentration in plasma (Fig. 6). No true hypoglycemia was documented in this patient during the study, although a hypoglycemic episode just before the observation cannot be ruled out.

\section{KETONURIA}

Acetonuria could not be correlated with levels of hormones in blood or urine, except possibly with high catecholamine excretion in $J C, J B$, and $J D$ (Figs. 5, 6), but " $4+$ " acetonuria preceded high catecholamine excretion in $J B$.

\section{DISCUSSION}

Our observations of blood sugar levels in these eight patients, as well as in other children who could not be subjected to such extensive studies, confirm the existence in children of wide swings in blood glucose, similar to those which were discovered by means of continuous blood glucose analysis in adult "unstable diabetics" by Molnar et al. $(38,49)$. These authors do not imply that hypoglycemia, noted in all of their records, was the cause of the instability.

Somogyi (51) demonstrated that both spontaneous and exogenous hyperinsulinism resulted in impaired glucose tolerance and that a state of "transient diabetes" could persist for 2 or 3 weeks, or even longer, after the removal of insulinomas. He insisted on attributing "the progressive deterioration of the carbohydrate tolerance in these cases to the cumulative diabetogenic effect of the repeated excitation of the adrenal-pituitary system by hypoglycemia."

Since Roth et al. (45) demonstrated the rise of plasma levels of growth hormone with starvation and with hypoglycemia in normal individuals, interest has centered on growth hormone as a major factor in raising glucose from hypoglycemic levels. Insulin-induced hypoglycemia is recognized as the appropriate stimulus for the growth hormone-releasing factor in the hypothalamus (40). A rapid fall of glucose, rather than a specific level, may be the most important stimulus to the secretion of growth hormone $(15,33)$.

Glucose intolerance becomes manifest within several hours after a (exogenous or endogenous) rise in growth hormone $(28,58)$. Mintz et al. (36) demonstrated glucose intolerance as early as 40 min after hypoglycemia produced by insulin injections in normal adults but not in growth hormone-deficient patients. They assumed the consistent rise of growth hormone secretion in their normal subjects to be the most likely cause of the glucose intolerance.

Since endogenous insulin is not produced in diabetic children, the hyperglycemic effect of the growth hormone might be expected to continue unchecked and to result in excessive hyperglycemia. Glick et al. (15) suggested in 1965 that increased secretion of growth hormone in response to hypoglycemia might contribute significantly to the "Somogyi effect." Our results in the first four patients $(D H, R H, R S$, and $F D)$ seemed to confirm this expectation. However, other observations did not establish a clear pattern. There was an occasional episode of hypoglycemia or a sharp fall of blood glucose which was not associated with a significant rise in the plasma level of growth hormone, and where the cause of the
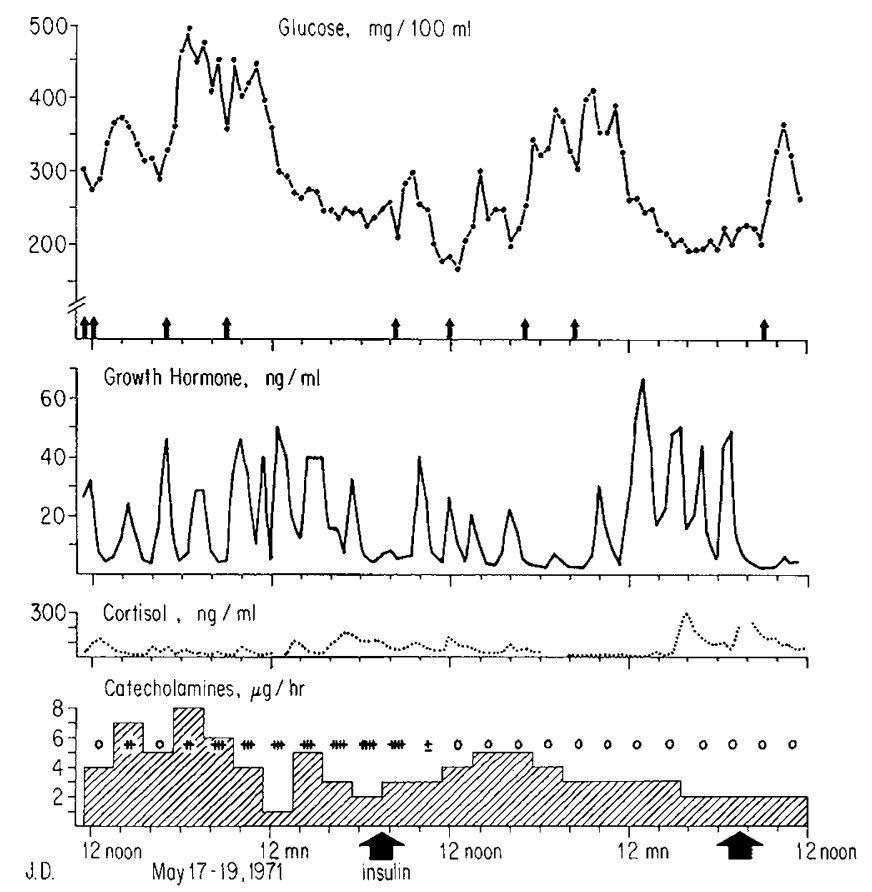

Fig. 6. Glucose in blood, growth hormone and cortisol in plasma, and total cạtecholamines in urine of $J D$, May 17-19, 1971. Symbols for acetone as in Figure 2. 17-OH-Corticoids were measured in the 2-hourly portions of urine; except for an excretion of $1.2 \mathrm{mg}$ in one 2-hr period, 1:30-3:30 PM on May 17, the amounts were all in the normal range; the total was $4.4 \mathrm{mg}$ in the first, $4.8 \mathrm{mg}$ in the second $24 \mathrm{hr}$. Insulin dose: Ultralente 42 units, regular 20 units. 
subsequent sharp rise of blood glucose was not evident from the hormone measurements. More frequently, like the patients of Fatourechi et al. (13), our patients had peaks of growth hormone concentration at times unrelated to hypoglycemia. This was particularly striking in $J D$ (Fig. 6). As noted in Table I, deep sleep could not explain the majority of the growth hormone peaks.

Molnar et al. (37) observed a rise in growth hormone level in response to "inadvertent" hypoglycemia in 27 out of 29 episodes when clinical manifestations were present, but only in 7 out of 17 asymptomatic episodes. They imply that a variety of physical and emotional stresses, other than hypoglycemia, may be responsible for growth hormone release in diabetic patients. The close interrelations between brain catecholamines and growth hormonereleasing factors $(6,35,39)$ may be most significant in diabetic children who are frequently subjected not only to hypoglycemia but also to emotional and other stresses. Rises of growth hormone in plasma in response to pain and emotional stress and, in diabetic children, with exercise, have been reported $(7,17,20,22)$.

On the other hand, the importance of asymptomatic and unsuspected episodes of hypoglycemia as causes of insulin resistance in diabetic patients has been emphasized by Somogyi (50), Bloom et al. (5), and Perkoff and Tyler (44); our own observations agree with theirs. Some investigators $(21,26,46)$ found growth hormone levels in plasma of juvenile, insulin-treated diabetic patients to be significantly higher, both in the fasting state and during glucose tolerance tests, than in untreated, adult, nonobese diabetic patients; and Sabeh et al. (46) suspect that "insulin therapy tends to raise growth hormone levels by sudden decreases in blood sugar or by actual hypoglycemia." Other investigators (10) found normal although variable growth hormone responses in insulin-treated diabetic children, except during ketoacidosis (12, $55)$ or with the stress of exercise.

Although neither the secretion of growth hormone in response to hypoglycemia nor its effects on blood glucose and glucose tolerance $(48,58)$ in normal humans and experimental animals is in doubt, it is less clear whether growth hormone release is the only, or even the main, cause of posthypoglycemic hyerglycemia in patients with brittle diabetes. The hormonal responses to acute hypoglycemia observed in normal individuals $(2,16,19,36,45)$ may not be the same as those of diabetic patients who have suffered repeated or prolonged episodes of hypoglycemia over many months or years. Most of the published cases of the Somogyi syndrome $(5,32,44,50,52)$, as well as our own cases $l-5(8)$, have had a history of excess insulin dosage for long periods. In these patients, the elevation of growth hormone levels in response to hypoglycemia or to a rapid fall in blood glucose and subsequent resistance to insulin seems to be fairly consistent, although a time relationship cannot be documented in every instance.

In normal persons, hypoglycemia produced by intravenous injection of insulin is followed in $30-60 \mathrm{~min}$ by a rise of the corticosteroids in plasma which is even more consistent than the elevation of growth hormone $(19,54)$. Corticosteroid levels in plasma as well as cortisol secretion rate are known to be elevated in diabetic acidosis $(24,29,53)$. In diabetic patients without acidosis, corticosteroid levels in plasma are reported in the normal range, although they are, on the average, slightly higher than in normal control subjects $(30,53)$. In the observations reported here, which include 12 episodes of acute hypoglycemia (blood glucose less than $60 \mathrm{mg} / 100 \mathrm{ml}$ ) during and after which plasma corticosteroids were measured, there was no indication that hypoglycemia per se provoked extraordinary secretion of cortisol. Although secretory phases accompanied many of the hypoglycemic episodes, the plasma levels of corticosteroids were no higher than at other times during the day, usually below $200 \mathrm{ng} / \mathrm{ml}$. Secretory phases, with peak levels usually below $200 \mathrm{ng} / \mathrm{ml}$, accompanied only half of 45 rapid falls of glucose (more than $100 \mathrm{mg} / 100 \mathrm{ml}$ in $2 \mathrm{hr}$ ). The higher levels of plasma corticosteroids seen in Figure 2, and of urinary 17-hydroxycorticoids in Figure 4 may have had other causes such as pain or emotional arousal. From these results, it appears unlikely that cortisol is an important mediator of the hyperglycemia which follows hypoglycemia in insulin-treated patients with juvenile diabetes. The abrupt and extensive rise of blood glucose which is seen in most of these patients at times is not a characteristic effect of an increase in either exogenous or endogenous cortisol in any case; however, the prolonged insulin resistance might conceivably be related to excessive cortisol action.

The response of the adrenal medulla to insulin-induced hypoglycemia was investigated by Wallace and Harlan (57) and by Goldfien et al. (16) by measuring plasma levels of epinephrine in normal subjects after intramuscular injections of insulin. A 10 15-fold rise of plasma epinephrine levels was observed; elevated epinephrine levels persisted for $2 \mathrm{hr}$. The authors emphasized that exogenous doses of epinephrine required to terminate the hypoglycemia far exceed the presumed secretion rate of the human adrenal medulla. In psychiatric patients receiving insulin shock therapy, the rise of the epinephrine level in plasma was considerably less on the 6th day of therapy, despite higher doses of insulin and lower blood levels of glucose, than on the 1 st day. The authors $(16,43,57)$ concluded that repeated insulin injections deplete adrenal stores of epinephrine and that resynthesis may require several days.

Abramson and Arky (1) concluded from studies with propranolol that endogenous epinephrine secretion is stimulated by insulin-induced hypoglycemia in normal human subjects and is responsible for the lipolysis and the increase of lactic acid in blood during the recovery period. However, since $\beta$-adrenergic blockade does not affect the influence of epinephrine on glycolysis in the liver, they could not prove that epinephrine is the essential factor causing the rise of blood glucose from hypoglycemic levels. The short duration of the elevation of blood glucose after epinephrine injection and the decreasing rate of epinephrine production after repeated episodes of hypoglycemia would be incompatible with the assumption that it is mainly this hormone which is responsible for the prolonged glucose intolerance which has been observed after repeated and prolonged states of hypoglycemia both by us and by others $(5,8,50,51)$.

This argument does not negate the concept that an acute increase in the release of endogenous epinephrine may be responsible for the ketosis and hyperglycemia associated with emotional arousal in some diabetic children, as suggested by Baker et al. (4), who were able to block what they assumed to be the lipolytic effect of endogenous catecholamines by $\beta$-adrenergic blockade and thus to reduce the episodes of ketoacidosis in their patients. Increased levels of catecholamines in plasma have also been observed with exercise in ketotic diabetic patients but not in well regulated cases (11).

Three of our patients $(J B, J C$, and $J D)$ excreted large amounts of catecholamines in the urine. The causes for this high production of catecholamines were not evident and may not have included hypoglycemia.

In some individuals, high secretion of growth hormone or catecholamines or both may be originally initiated by psychogenic or other stimuli; these hormones may cause hyperglycemia and excessive glycosuria which lead the therapist to use high insulin dosage which, in turn, results in hypoglycemia at times. This possibility was suggested particularly in the two adolescent girls, $K L$ and $J D$, who had the highest and most frequent peaks of growth hormone concentration. At the time of the tests, $K L$ was fully mature; $J D$ was a few months before her menarche. Enhanced response of growth hormone secretion to various stimuli has been observed in women compared with men and in men when under the effect of estrogens $(14,34)$. It is possible that these responses are at least in part responsible for the clinically often noted extreme instability of some female adolescents and young adults.

Ketonuria has been well recognized as a feature of the Somogyi syndrome $(5,50)$. Ketosis is the result of rapid lipolysis. The $\beta$-adrenergic action of the catecholamines is the best documented hormonal stimulus to lipolysis (9). Observations of Hollobaugh et al. (23) suggest that lipolysis may occur in vivo in humans under the influence of high levels of growth hormone as well as of catecholamines. The lipolytic effect of endogenous cortisol or glucagon in humans is less well documented; in dogs, Altszuler et 
al. (3) provoked lipolysis with epinephrine but not with a dose of glucagon which raised blood glucose to an equivalent level.

Although ketonuria occurred in most of our patients at one time or another, no consistent time relationship to hypoglycemic episodes was apparent. There was no significant ketonuria in $D H$ and $R S$ at the time of the most severe Somogyi effect. The occurrence of ketonuria could not be correlated with the levels of growth hormone or cortisol in plasma; where it seemed to be correlated with the catecholamine excretion, the time relationships indicate that this catecholamine production could not have been a response to hypoglycemia, since the response of epinephrine secretion to hypoglycemia is an immediate one.

Our studies of catecholamine excretion do not provide a clear picture of the role of these hormones in the genesis of posthypoglycemic hyperglycemia. Of the urinary secretion of catecholamines, $80-90 \%$ normally consists of norepinephrine and its metabolites, whereas it is epinephrine which produces hyperglycemia. A 5- or 10-fold increase in epinephrine production might have a hardly noticeable effect on the total amount of catecholamines in the urine if it were not accompanied by an increase in norepinephrine. The two hormones or their metabolites in the urine will have to be measured individually to determine their role in the response to hypoglycemia.

Evaluation of the role of glucagon secretion in the response of diabetic children to hypoglycemia and attempts to identify the contribution of epinephrine and its metabolites to the total urinary excretion of catecholamines will be the objects of future studies. At present, it appears possible that in different patients, or in the same patient at different times, a different combination of hormonal responses operates, among which growth hormone secretion is most prominent.

\section{SUMMARY}

Half-hourly measurements of levels of glucose, endogenous growth hormone, and corticoids in the blood of children suspected of suffering from the Somogyi syndrome indicated that peaks of growth hormone concentration were most frequently, although not always, associated with low or falling glucose concentration and were followed by often prolonged hyperglycemia and apparent insulin resistance. Large amouts of catecholamines were excreted by several children, but since the respective contributions of epinephrine $v s$ other catecholamines were not identified, their role in the wide fluctuations of blood glucose cannot be interpreted. Secretory phase of corticosteroids, with peak levels usually below $200 \mathrm{ng} / \mathrm{ml}$, accompanied only half of the episodes of rapid fall of glucose level. It is suspected that both the causes and the pattern of stimulation of "anti-insulin hormones" may vary from patient to patient, but that one or more of these hormones are responsible for the hyperglycemic phases of "brittle" diabetes in children. The pertinent literature is reviewed and discussed.

\section{REFERENCES AND NOTES}

1. Abramson, E. A., and Arky, R. A.: Role of beta-adrenergic receptors in counterregulation to insulin-induced hypoglycemia. Diabetes, 17: 141 (1968).

2. Abramson, E. A., Arky, R. A., and Woeber, K. A.: Effects of propranolol on the hormonal and metabolic responses to insulin-induced hypoglycaemia. Lancet, ii: 138624 (1966)

3. Altszuler, N., Morrison, A., Steele, R., and Bjerkness, C.: Metabolic effects of epinephrine, dibutyryl cyclic AMP, and glucagon infused intravenously into normal dogs. Ann. N. Y. Acad. Sci., 185: 101 (1971).

4. Baker, L., Barcai, A., Kaye, R., and Haque, N.: Beta adrenergic blockade and juvenile diabetes: Acute studies and long-term therapeutic trial. J. Pediat., 75: 19 (1969).

5. Bloom, M. E., Mintz, D. H., and Field, J. B.: Insulin-induced posthypoglycemic hyperglycemia as a cause of brittle diabetes: Clinical clues and therapeutic implications. Amer. J. Med. 47: 891 (1969).

6. Boyd, A. E., III, Lebovitz, H. E., and Pfeiffer, J. B.: Stimulation of humangrowth-hormone secretion by L-DOPA. New Engl. J. Med., 283: 142524 (1970).

7. Brown, G. M., and Reichlin, S.: Psychologic and neural regulation of growth hormone secretion. Psychosom. Med., 34: 45 (1972).

8. Bruck, E., and MacGillivray, M. H.: Post-hypoglycemic hyperglycemia in diabetic children. J. Pediat., 84: 672 (1974)

9. Burns, T. W., Langley, P. E., and Robison, G. A.: Adrenergic receptors and cyclic AMP in the regulation of human adipose tissue lipolysis. Ann. N. Y.
Acad. Sci., 185: 115 (1971).

10. Chiumello, G., del Guercio, M. J., Carnelutti, M., Devetta, M., Rossi, L., and Caccamo, A.: The role of growth hormone in the pathogenesis of diabetes mellitus in childhood. J. Pediat., 79: 768 (1971).

11. Christensen, N. J.: Abnormally high plasma catecholamines at rest and during exercise in ketotic juvenile diabetics. Scand. J. Clin. Lab. Invest., 26: 343 (1970).

12. Cryer, P. E., and Daughaday, W. H.: Diabetic ketosis: Serial plasma growth hormone concentrations during therapy. Diabetes, 19: 519 (1970).

13. Fatourechi, V., Molnar, G. D., Service, F. J., Ackerman, E., Rosevear, J. W., Moxness, K. E., and Taylor, W. F.: Growth hormone and glucose interrelationships in diabetes: Studies with insulin infusion during continuous blood glucose analysis. J. Clin. Endocrinol. Metab., 29: 319 (1969).

14. Frantz, A. G., and Rabkin, M. T.: Effects of estrogen and sex difference on secretion of human growth hormone. J. Clin. Endocrinol. Metab., 25: 1470 (1965).

15. Glick, S. M., Roth, J., and Yalow, R.: The regulation of growth hormone secretion, Recent Progr. Hormone Res., 21: 241 (1965).

16. Goldfien, A., Moore, R., Zileli, S., Havens, L. L., Boling, L., and Thorn, G. W.: Plasma epinephrine and norepinephrine levels during insulin-induced hypoglycemia in man. J. Clin. Endocrinol. Metab., 21: 296 (1961).

17. Greene, W. A., Conron, G.. Schalch, D. S., and Schreiner, B. F.: Psychologic correlates of growth hormone and adrenal secretory responses of patients undergoing cardiac catheterization. Psychosom. Med., 32: 599 (1970).

18. Greenwood, F. C., Hunter, W. M., and Glover, J. S.: The preparation of ${ }^{131} \mathrm{I}$-labeled human growth hormone of high specific radioactivity. Biochem. J., 89: 114 (1963).

19. Greenwood, F. C., Landon, J., and Stamp, T. C. B.: The plasma sugar, free fatty acid, cortisol, and growth hormone response to insulin. I. In control subjects. J. Clin. Invest., 45: 429 (1966).

20. Hansen, A. P.: Abnormal serum growth hormone response to exercise in juvenile diabetics. J. Clin. Invest., 49: 1467 (1970).

21. Hansen, A. P., and Johansen, K.: Diurnal patterns of blood glucose, serum free fatty acids, insulin, glucagon and growth hormone in normals and juvenile diabetics. Diabetologia, 6: 27 (1970).

22. Helge, H., Weber, B., and Quabbe, H. J.: Growth hormone release and venepuncture. Lancet, $i: 204$ (1969)

23. Hollobaugh, S. L., Tzagournis, M., Folk, R. L., Kruger, F. A., and Hamwi, G. J.: The diabetogenic action of human growth hormone: Glucose-fatty acid interrelationships. Metabolism, 17: 485 (1968).

24. Jacobs, H. S., and Nabarro, J. D. N.: Plasma 11-hydroxycorticosteroid and growth hormone levels in acute medical ilinesses. Brit. Med. J., L: 595 (1969).

25. Jacobs, S. L., Sobel, C., and Henry, R. J.: Specificity of the trihydroxyindole method for determination of urinary catecholamines. J. Clin. Endocrinol. Metab., 21: 305 (1961).

26. Johansen, K., and Hansen, A. P.: Diurnal serum growth hormone levels in poorly and well-controlled juvenile diabetics. Diabetes, 20: 239 (1971).

27. Jusko, W. J., Slaunwhite, W. R., Jr., and Aceto, T., Jr.: Partial pharmacodynamic model for the circadian-episodic secretion of cortisol in man. J. Clin. Endocrinol. Metab., 40: 278 (1975).

28. Kipnis, D. M.: Growth hormone and insulin antagonism. In: B. S. Leibel and G. A. Wrenshall: On the Nature and Treatment of Diabetes, p. 258 (Excerpta Medica Foundation, Amsterdam, 1965).

29. Klein, R., Papadatos, C., Fortunato, J., and Byers, C.: Acid-hydrolyzable corticoids of serum. J. Clin. Endocrinol. Metab., 15: 215 (1955).

30. Klein, R., Weigand, F. A., Iunes, M., and Greenman, L.: Corticoids in serum of children with treated diabetes mellitus. Pediatrics, 17: 214 (1956).

31. Krieger, D. T., Allen, W., Rizzo, F., and Krieger, H. P.: Characterization of the normal temporal pattern of plasma corticosteroid levels. J. Clin. Endocrinol. Metab., 32: 266 (1971)

32. Lavietes, P. H., and Peters, J. P.: The treatment of diabetes. Intern. Clin., 2: 170 (1941).

33. Luft, R., Cerasi, E., Madison, L. L., von Euler, U. S., Della Casa, L., and Roovete, A.: Effect of a small decrease in blood-glucose on plasma-growth hormone and urinary excretion of catecholamines in man. Lancet. ii: 254 (1966).

34. Merimee, T. J., Burgess, J. A., and Rabinowitz, D.: Sex-determined variation in serum insulin and growth hormone response to amino acid stimulation. J. Clin. Endocrinol. Metab., 26: 791 (1966).

35. Merimee, T. J., and Rabin, D.: A survey of growth hormone secretion and action. Metabolism, 22: 1235 (1973).

36. Mintz, D. H., Finster, J. L., Taylor, A. L., and Fefer, A.: Hormonal genesis of glucose intolerance following hypoglycemia. Amer. J. Med., 45: 187 (1968).

37. Molnar, G. D., Fatourechi, V., Ackerman, E., Taylor, W. F., Rosevear, J. W., Gatewood, L. C., Service, F. J., and Moxness, K. E.: Growth hormone and glucose interrelationships in diabetes: Studies of inadvertent hypoglycemic episodes during continuous blood glucose analysis. J. Clin. Endocrinol. Metab., 32: 426 (1971)

38. Molnar, G. D., Taylor, W. F., Langworthy, A., and Fatourechi, V.: Diurnal growth hormone and glucose abnormalities in unstable diabetics: Studies of ambulatory-fed subjects during continuous blood glucose analysis. J. Clin. Endocrinol. Metab., 34: 837 (1972).

39. Muiller, E. E.: Brain catecholamines and growth hormone release. In: W. Bargman and B. Scharrer: Aspects of Neuro-endocrinology, Fifth International Symposium on Neurosecretion. August 20-23, 1969, Kiel (Springer Verlag. New York, 1970)

40. Müller, E. E., Saito, T., Arimura, A., and Schally, A. V.: Hypoglycemia, stress and growth hormone release: Blockade of growth hormone release by drugs acting on the central nervous system. Endocrinology, 80: 109 (1967). 
41. Murphy, B. E. P.: Some studies of the protein-binding of steroids and their application to the routine micro and ultramicro measurement of various steroids in body fluids by competitive protein-binding radioassay. J. Clin. Endocrinol. Metab., 27: 973 (1967).

42. Nelson, N.: A photometric adaptation of the Somogyi method for the determination of glucose. J. Biol. Chem., 153: 375 (1944).

43. Outschoorn, A. S.: The hormones of the adrenal medulla and their release. Brit. J. Pharmacol., 7: 605 (1952)

44. Perkoff, G. T., and Tyler, F. H.: Paradoxical hyperglycemia in diabetic patients treated with insulin. Metabolism, 3: 110 (1954)

45. Roth, J., Glick, S. M., Yalow, R. S., and Berson, S. A.: Hypoglycemia: A poten stimulus to secretion of growth hormone. Science, 140: 987 (1963)

46. Sabeh, G., Mendelsohn, L. V., Corredor, D. G., Sunder, J. H., Friedman, L. M., Morgan, C. R., and Danowski, T. S.: Growth hormone in insulin-treated diabetes mellitus. Metabolism, 18: 748 (1969).

47. Schalch, D. S., and Parker, M. L.: A sensitive double antibody immunoassay for human growth hormone in plasma. Nature, 203: 1141 (1964).

48. Schnure, J. J., Raskin, P., and Lipman, R. L.: Growth hormone secretion during sleep: impairment in glucose tolerance and nonsuppressibility by hyperglycemia. J. Clin. Endocrinol. Metab., 33: 234 (1971).

49. Service, F. J., Molnar, G. D., Rosevear, J. W., Ackerman, E., Gatewood, L. C. and Taylor, W. F.: Mean amplitude of glycemic excursions, a measure of diabetic instability. Diabetes, 19: 644 (1970).

50. Somogyi, M.: Exacerbation of diabetes by excess insulin action. Amer. J. Med. 26: 169 (1959).

51. Somogyi, M.: Diabetogenic effect of hyperinsulinism. Amer. J. Med., 26: 192 (1959)

52. Somogyi, M., and Kirstein, M. B.: Insulin as a cause of extreme hyperglycemia and instability. Week. Bull. St. Louis Med. Soc., 32: 498 (1938),

53. Sperling, M. A.. Bacon, G., Kenny, F. M., and Drash, A. L.: Cortisol secretion in acidotic and nonacidotic diabetes mellitus. Amer. J. Dis. Child., I24: 690
(1972).

54. Tietze, H. U., Zurbrügg, R. P Zuppinger, K. A., Joss, E. E., and Käser, H : Occurrence of impaired cortisol regulation in children with hypoglycemia associated with adrenal medullary hyporesponsiveness. J. Clin. Endocrinol. Metab., 34: 948 (1972)

55. Unger, R. H.: High growth-hormone levels in diabetic ketoacidosis: A possible cause of insulin resistance. J. Amer. Med. Ass., 191: 945 (1965).

56. Voorhess, M. L.: Urinary catecholamine excretion by healthy children. I. Daily excretion of dopamine, norepinephrine, epinephrine and 3-methoxy-4hydroxymandelic acid. Pediatrics, 39: 252 (1967).

57. Wallace, J. M., and Harlan, W. R.: Significance of epinephrine in insulin hypoglycemia in man. Amer. J. Med., 38: 531 (1965).

58. Yalow, R S. Goldsmith, S. J., and Berson, S. A. Influence of physiologic fluctuations in plasma growth hormone on glucose tolerance. Diabetes, $18: 402$ (1969).

59. Bio-Science Laboratories, Van Nuys, Calif

60. This work was performed in the Clinical Research Center of the Children's Hospital of Buffalo, supported by a grant (RR 628) from the General Clinical Research Centers Program of the Division of Research Resources, National Institutes of Health. It was also supported by the Department of Health, Education and Welfare, Maternal and Child Health Service (Project 417). Parts of this material were presented in the Endocrinology Section at the joint meeting of the American Pediatric Society and the Society for Pediatric Research in Atlantic City, April 30, 1971; in the Round Table on Diabetes Mellitus at the XIIIth International Congress of Pediatrics, Vienna, September 1971: and in a lecture to the pediatric staff of the Georgetown University Hospital, Washington, D.C. October 29, 1971 in the course of a Visiting Professorship sponsored by the Journal of Pediatrics Educational Foundation.

61. Requests for reprints should be addressed to: E. Bruck, M. D., Children's Hospital of Buffalo, 219 Bryant St., Buffalo, N. Y. 14222 (USA).

62. Accepted for publication March 10, 1975.
Agammaglobulinemia lymphocytes $\mathrm{B}$ cell disorders immunoglobulin

\title{
The Use of Transfer Factor in a Patient with Agammaglobulinemia
}

\author{
NIEVES M. ZALDIVAR, (39) PHOTINI S. PAPAGEORGIOU, SARAH KAFEE, AND \\ PHILIP R. GLADE \\ Department of Pediatrics, Division of Infectious Diseases, Mount Sinai School of Medicine of the City \\ University of New York, New York, New York, USA
}

Extract

We have studied a 9-year-old boy with agammaglobulinemia treated for the past 6 years with exogenous $\gamma$-globulin who was noted to have an immunoglobulin (Ig) $M$ level of $35 \mathrm{mg} / 100 \mathrm{ml}$ and circulating $B$ cells as determined by immunofluorescence. Of the circulating lymphocytes, $41 \%$ had $\alpha$-immunoglobulin heavy chains, 3\% $\gamma$ chains, and 3\% $\mu$ chains. Synthesis of $\gamma$ heavy chain classes showing wide heterogeneity and $\alpha$ and $\mu$ chains of restricted mobility was demonstrated by radioimmunoelectrophoresis. Because of the patient's poor clinical response to exogenous $\gamma$-globulin administration and the paradoxic presence of circulating $B$ cells, with the capacity to synthesize immunoglobulins in vitro, we elected to begin a course of therapy with transfer factor. After the initial four doses of transfer factor $\left(2 \times 10^{8}\right.$ lymphocytes/dose $)$ his serum IgG rose from 50 to $130 \mathrm{mg} / 100 \mathrm{ml}$, the same level which he had previously attained during continuous exogenous $\gamma$-globulin therapy. His serum IgG has remained at this level for the past 12 months with trimonthly booster doses of transfer factor. The patient has not required any additional $\gamma$-globulin therapy and he has remained clinically asymptomatic.

\section{Speculation}

Our studies in a patient with agammaglobulinemia have shown that transfer factor therapy may affect immunoglobulin synthesis. The concurrent discontinuation of exogenous $\gamma$-globulin administration makes it difficult to attribute the changes to only one or another aspect of therapy. We await further reports of the effects of transfer factor in the therapy of patients with B cell disorders.

Congenital agammaglobulinemia has been considered a stem cell deficiency involving thymic-independent B lymphocytes with sparing of thymic-dependent $T$ lymphocytes. The paradoxic finding of $\mathrm{B}$ lymphocytes with surface immunoglobulins and receptors for complement in the peripheral circulation of some patients with agammaglobulinemia $(16,19)$, however, argues against a stem cell origin for this disorder. Extensive investigations in the mouse confirm that $\mathrm{T}$ lymphocytes are instrumental in the facilitation and suppression of immunoglobulin and antibody production by $B$ lymphocytes (13). Recent studies in man have further demonstrated a variable $T$ lymphocyte deficiency in some patients with the clinical and laboratory manifestations of congenital agammaglobulinemia (21). These findings suggest that the B cell dysfunc- 